\title{
Task-based Language Teaching in General English Classrooms: A Case Study in Engineering Faculties in Iran
}

\author{
Farnaz Latif \\ Department of English Language, Yadegar-e-Imam Khomeini (RAH) Shahre Rey Branch, Islamic Azad University, Tehran, Iran \\ Email: farnaz.latif@gmail.com \\ Mahdieh Shafipoor \\ Department of English Language Translation, Shahr-e-Qods Branch, Islamic Azad University, Tehran, Iran \\ Email: ma.shafipoor@gmail.com
}

\section{Doi:10.5901/mjss.2015.v6n4p587}

\begin{abstract}
Teaching General English, as a fundamental course in all the non-English majors, at universities in Iran has constantly been considered vital among the scholars' concerns. Thus, the TEFL researchers have always attempted to study and analyze the currently practice teaching methodologies at different levels in order to introduce the most efficient ones to the practitioners in the field. Therefore, to improve the quality and efficiency of teaching general English at universities, the researchers in the present study have tried to explore the currently practiced general English teaching methodologies for engineering students in Islamic Azad University, Yadegar-e Emam Khomeini (RAH) Shahre Rey Branch. In other words, they have attempted to reflect on a comparative study of two globally popular teaching methodologies namely; Task-based and Task- supported at this university to present the more efficient one to the target community.
\end{abstract}

Keywords: General English, Task-based Teaching, Task-supported teaching, ESP, Task

\section{Introduction}

Ample tendency toward task-based language learning and teaching has been traced during the last two decades (e.g., Ellis, 2000, 2003; Skehan; 2003b and Littlewood, 2004). The underlying impetus for such orientation might be sophisticated, as Willis states (1996, in Swan, 2005:378), it probably provides the opportunity to integrate 'the best insights from communicative language teaching with an organized focus on language form' and thus evades the demerits of rather scrutinizing form-focused or communication-oriented approaches. A number of studies have shed light over the significance of encouraging learners to 'notice' or attend to language forms or to promote each other to do so (e.g., Doughty and Varela, 1998; Murphy, 2005) whether within or outside the formal pedagogical environment. Foster and Skehan (1999:216) point out that the form-focused approaches have immensely been substituted by a stress on meaningful tasks looking for the opportunities to equally attend both accuracy and fluency. Nevertheless, they further note that 'learners have limited attention capacities and that the very different aspects of comprehension and language production, i.e. accuracy, complexity and fluency, compete for these capacities'. Van Patten (1990; 1996, in Ellis, 2001:8) proposes that learners have difficulties in simultaneously taking both form and meaning into account and often prioritize one at the expense of the other. According to Lightbown and Spada (1993:105), 'classroom data from a number of studies offer support for the view that form-focused instruction and corrective feedback provided within the context of a communicative program are more effective in promoting second language learning than programs which are limited to an exclusive emphasis on accuracy on the one hand or an exclusive emphasis on fluency on the other.'

\section{Literature Review}

\subsection{Task and its definitions}

According to Ellis (2003) Tasks have been placed at the core of the current studies in both SLA research and in language pedagogy. But the emerging question is that of the definition of task. It should be attested that there is no mutual agreement on the constituent components of a task in the literature, though. While focusing on the following dimensions, 
Ellis (2003) in his book entitled Task-based Language Learning and Teaching presents a number of definitions of the term in: (1) the scope of a task; (2) the perspective from which a task is viewed; (3) the authenticity of a task; (4) the linguistic skills required to perform a task; (5) the psychological processes involved in task performance, and (6) the outcome of a task.

Furthermore, Littlewood's (2004) approach toward the definitions of 'task' will be clarified. Littlewood (2004:320) defines 'task' through various definitions along a continuum ' the extent to which they insist on communicative purpose as an essential criterion.' His stated continuum can be studied based on three points whose emphasis starts from the least on form and the most on meaning: According to Zhao (2011) some scholars do not consider communicative purpose as a crucial criterion. He refers to the example definition by Breen (1987, in Ellis, 2003:4), which defines a task as 'a structured plan for the provision of opportunities for the refinement of knowledge and capabilities entailed in a new language and its use during communication'. He specifically states that a 'task' can be 'a brief practice exercise' or 'a more complex work plan that requires spontaneous communication of meaning'. Estaire and Zanon (1994: 13) follow this broad definition but classify task to two main categories: 'communicative tasks', in which the 'learner's attention is focused on meaning rather than form', and 'enabling tasks', in which the 'main focus is on linguistic aspects (grammar, vocabulary, pronunciation, functions, and discourse).'

Studying through the continuum, some scholars are reluctant to adopt a purely communicative-oriented definition for tasks. In fact, they consider tasks initially as those entailing communication (Zhao, 2011). Thus, Stern (1992:195) associates tasks with 'realistic language use' when he proposes that 'communicative exercises provide opportunities for relatively realistic language use, focusing the learner's attention on a task, problem, activity, or topic, and not on a particular language point'.

Moving still further along the continuum, some researchers tend to confine the use of the term to activities which are primarily meaning-centered. For instance, Nunan's (1989) definition elaborates on the point that 'a task is a piece of classroom work which involves learners in comprehending, manipulating, producing, or interacting in the target language while their attention is principally focus on meaning rather than form. The task should have a sense of completeness, being able to stand alone as a communicative act in its own right'. Moreover, Skehan (1996) states that 'a task is an activity in which meaning is primary; there is some sort of relationship to the real world; task completion has some priority; and the assessment of task performance is in terms of outcome'.

\subsection{Principles and procedures of TBLT}

The concept of 'task' has constantly played a fundamental role in syllabus design, classroom teaching methodologies and learner assessment. Thus, it has drawn the attention of numerous studies to itself and the results of these studies have successfully and directly influenced ESL policy making procedure and outcome (Nunan2004). Designing lessons based on TBLT entails consideration of stages and components which take 'task' as the main and central factor. Following this perception, different models have been introduced (Estaire\&Zanon, 1994; Lee, 2000; Prabhu, 1987; Skehan, 1996, 2009; Willis, 1996; Ellis 2013; Willis \& Willis 2007). However, all of these models entail three common phases. The first phase is the pre-task which focuses on the application of various tasks adopted by the instructors before carrying out the main tasks. The second phase is the main task which centers on tasks with different educational and contextual focus. And the final phase is the post task which includes the processes based on the main task. However, the only obligatory task is the main task (Willis 2007).

Task-Based Language Teaching (TBLT) is informed by principles rooted in theories of and research into secondlanguage learning and teaching (Ellis, 2003; Samuda\&Bygate, 2008; Swan). The following is a summary of the most crucial principles (Bygate, Skehan, \& Swain, 2001; Candlin, 2001; Ellis; Long, 1991; Nunan, 1991, 1993; Richards \& Rogers, 2001; Samuda\&Bygate; Skehan, 1998, 2003; Willis, 1996).

- Learners need exposure to the authentic and different language of speakers of the target language (often modified; always comprehensible).

- Learners must be exposed to and adopt the kind of language that they want and need for their own interests or purposes.

- Learners must be provided with opportunities for unrehearsed and meaningful language use in purposeful interaction, where they take informed risks, make choices, and negotiate meaning while seeking solutions to genuine queries.

- Teachers ensure that activities are interconnected and organized with clearly specified

- objectives and promote the desire to learn.

- Teachers should elicit self-correction, enable personalized feedback, and consider learners'individual 
developing language systems (interlanguage).

- Teachers must set learners activities that help them notice language forms; induction/discovery is preferable to deduction/presentation; teachers should (explicitly) instruct form in the context of activities where meaning is primary.

- The whole language (listening, speaking, reading, and writing) should be integrated.

- Learners Evaluation by the Teachers takes place in a formative manner and in terms of the process of achieving a goal; learners need to evaluate their own performance and progress.

\subsection{Task based courses}

In general, a course design entails the processes of selection and sequencing of the subject matter content or what Ellis (2003) calls upon 'what' of teaching as compared to 'how' of teaching which is similar to the term "methodology". It has been proposed, though, that task-based instruction does not attend the distinction between 'design' and 'methodology'.

According to Nunan (1989), in Task- based language teaching the focus turns from the 'outcomes of instruction ' to the 'process of instruction' i.e. respectively from the linguistic knowledge of skills to be mastered to what the learners need to do in order to learn. Therefore, he takes an integrative view concerning both 'how' and 'what' of teaching. In line with Nunan(1989), Kumaravalivelu (1993) considers methodology as the 'central tenant of task-based pedagogy'(p.37)since he points out that the underlying objective of a particular methodology is to permit the learners to navigate their own routs toward learning.

In fact, a task-based curriculum entails decision making over the content -i.e. the selection of the tasks to be included in the syllabus, and methodology -i.e. how to employ these tasks in the classroom . Therefore, it is vital to take the distinction into account when there is a discussion over task-based instruction. Ellis(2003) in an article entitled 'taskbased language teaching' specifies how the activities in a syllabus can be converted into real lessons i.e. lesson design and how both learners and the instructor can take part in such lessons -what he names 'participatory structure' .

\subsection{Research Objective}

General English is one of the fundamental courses in all university majors in Iran. In addition, it generally entails a total 3 educational credit. However, unfortunately, a significant gap has been observed between the practiced teaching methodologies and the consequent pedagogical output achieved. In fact, this gap has had negative impact on General English and then ESP students' achievements and success at the nationwide universities. To this end, one of the issues in TEFL which has been among the most challenging concerns and mostly ignored by the researchers in the field is exploring the aforementioned gap and trying to present the most efficient and effective solutions to the target Iranian community . In other words, adopting particular teaching methods and observing their impacts on the practical quality of the general English learning process will positively influence the learners' pedagogical success in higher levels (ESP).

\subsection{Research questions}

In the present study the researchers tried to focus on and address engineering faculties' GE instructors' perceptions to answer the following questions;

1. What are the participant GE instructors' attitudes towards the implementation of TBLT ?

2. How well do the participant GE instructors perceive TBLT concepts?

\section{Method}

\subsection{Participants}

In this study, 110 General English university instructors from different branches of Islamic Azad University namely; Central Branch, South Branch and Yadegar-e-Imam Khomeini (RAH) Shahre Rey attended. Among them, 10 instructors were selected to attend the semi-structured interview, 100 instructors replied the questionnaires to estimate the generalizability of the statements in the questionnaires through Frequency analysis. All the participants at least held MA and at most PhD degrees in TEFL and had at least 5 years experience of teaching GE at universities. 


\subsection{Instruments}

To fulfill the purpose of the study, the following instruments were deployed:

\subsubsection{Semi-structured Interview questions}

At this stage of the study, 10 participant General English instructors from the engineering faculty of Islamic Azad University, Yadegar-e-Imam Khomeini (RAH) Shahre Rey answered the following questions in a semi-structured interview session:

- Explain about the course book you are teaching. It is said to be a task-based source book. What do you think?

- How do you personally define a "task"?

- What is task-based language teaching? Have you ever applied it in your classes at university?

- Elaborate on your instructional techniques in General English classes. How do you apply TBLT to cover the assigned syllabus within 12 sessions?

- How successful is a task-based course book in general English courses?

\subsubsection{Questionnaire}

A 5 -scaled lickert questionnaire was used to measure Iranian engineering general English instructors' perceptions toward TBLT at universities. This questionnaire was adopted from (Hadi. A, 2013) and then modified to suit the purpose of the study. The questionnaire entailed three sections, the first section evaluated the participant instructors' background knowledge in general, the second section focused on their perception of the concept of 'task' and 'TBLT' and the third section centered on their willingness or reluctance towards the deployment of TBLT in their general English classes at university.

\subsection{Research Design}

The research design of the present study was mixed method design and of qualitative-quantitative type. The qualitative phase of the study has been carried out through the application of a semi-structured interview with $10 \mathrm{GE}$ instructors. Then, to proceed through the qualitative phase, after transcription and coding the interview responses, the researchers distributed the 5- scaled lickert questionnaire to conduct the frequency analysis and came up with generalization of the participants' statements.

\subsection{Data Collection Procedure}

The researchers visited $10 \mathrm{GE}$ instructors of the engineering faculty of Islamic Azad branch Yadegar-e-Imam Khomeini (RAH) Shahre Rey and explained and clarified the purpose of the study and then asked them to participate in the semistructured interview stage. The whole process took one month and then as the responses were collected, transcribed and coded the data collection and analysis simultaneously took place. Finally at the quantitative stage, 100 questionnaires were distributed among the GE instructors at different branches of Islamic Azad University to calculate the frequency of the statements.

\subsection{Data Analysis}

The data analysis process consisted of two phases: 1) semi-structured interview response transcription and coding to analyze the participant GE instructors' statements concerning their personal perception of TBLT and their classroom performance.2)The 5- scaled Likert questionnaire which consisted of three sections was constructed to check teachers' awareness of TBLT principles and their views on TBLT implementation, the participants' responses were given a numerical score (e.g., strongly disagree $=1$, disagree $=2$, neutral $=3$, agree $=4$, and strongly agree $=5$ ). Then the responses were analyzed through frequency analysis by SPSS. 


\section{Results}

\subsection{Qualitative phase: semi-structured interview}

At this phase the responses of the 10 participant GE instructors' were transcribed and coded. As a result, the following statements were commonly traced in their responses.

- They mutually reflected on a tendency toward frequent adoption of pre-tasks outside the course book as warm-up tasks to the lessons.

- They commonly were willing to promote creativity through the pre-task selection process. They believed that this would increase learners' motivation and will add synergy to the classroom atmosphere.

- They all emphasized on the need to use tasks which are in line with the learners' interests in a General English classroom and relevant to their individual background knowledge.

- They called the trend of following the general English course book tasks in the prescribed order of the book a failure. In their opinion, the reason behind this failure was ignorance of the pre-tasks.

- The instructors stressed on the significance of language-centered assessment at the pre-task stage to increase the efficiency of the pre-tasks.

- They further elaborated on the importance of group work activities to increase the instructional efficiency.

\subsection{Quantitative phase: questionnaire}

\subsubsection{Addressing the First Research Question}

This part is related to the first research question that states: How well do GE instructors understand TBLT concepts? Section two of the questionnaire contained seven items dealing with this question. Table 1 shows the result of the Instructors' reactions to this section.

Table 4.1 GE instructors' responses to section II of the questionnaire

\begin{tabular}{|c|c|c|c|c|c|}
\hline Question & SA & A & $U$ & D & SD \\
\hline 1 & 65 & 10 & 0 & 20 & 10 \\
\hline 2 & 10 & 35 & 2 & 50 & 3 \\
\hline 3 & 27 & 0 & 10 & 40 & 23 \\
\hline 4 & 42 & 0 & 13 & 45 & 0 \\
\hline 5 & 70 & 7 & 3 & 20 & 0 \\
\hline 6 & 46 & 36 & 0 & 21 & 0 \\
\hline 7 & 40 & 50 & 10 & 0 & 0 \\
\hline \multicolumn{7}{|l|}{ SA= strongly agree; A= agree; Undecided ; D= disagree; SD= strongly disagree } \\
\hline
\end{tabular}

Exploring the results presented in Table 1, it can be found that the majority of the GE instructors generally agreed with the items, and there was almost $36 \%$ strong disagreement on the first three items. For item one "a task is communicative goal directed" $65.1 \%$ strongly agreed and $10 \%$ just agreed, and there was $30 \%$ disagreement. Item two "a task involves a primary focus on meaning" had $10 \%$ strong agreement, 35\% agreement, $2 \%$ neutral responses, and $50 \%$ disagreement, and $3 \%$ strong disagreement. Regarding item three "a task has a clearly defined outcome", $27 \%$ strongly agreed, 10\% were neutral, $40 \%$ disagreed, and $23 \%$ strongly disagreed. For item four "a task is any activity in which the target language is used by the learner", $42 \%$ showed strong agreement, $13 \%$ were neutral, while $45 \%$ disagreed. As with item five "TBLT is consistent with the principles of communicative language teaching", $70 \%$ strongly agreed, $7 \%$ agreed, and $3 \%$ were neutral whereas $20 \%$ disagreed. Item six "TBLT is based on the student-centered instructional approach" collected $46 \%$ strong agreement, 36\% agreement, and 21\% disagreement. Considering the last item, that is, item seven "TBLT includes three stages: pre-task, task implementation, and post-task", 40\% strongly agreed, $50 \%$ agreed, 10\% were neutral, and there was no disagreement.

\subsection{Addressing the Second Research Question}

This part relates to the second research question that states: What are the aspects of GE instructors' views on TBLT 
implementation? Section three of the questionnaire consisted of eight items which corresponded to this question. Table 2 depicts the results of the GE instructors' responses to the items of section three of the questionnaire.

Table 4.2. The Results of the GE Instructors' Responses to Section III

\begin{tabular}{|c|c|c|c|c|c|}
\hline Question & SA & A & $U$ & $D$ & SD \\
\hline 1 & 50 & 6 & 4 & 0 & 40 \\
\hline 2 & 0 & 16 & 0 & 9 & 70 \\
\hline 3 & 37 & 33 & 14 & 0 & 2 \\
\hline 4 & 65 & 34 & 1 & 0 & 0 \\
\hline 5 & 70 & 0 & 5 & 15 & 10 \\
\hline 6 & 5 & 10 & 65 & 20 & 0 \\
\hline 7 & 77 & 10 & 0 & 0 & 22 \\
\hline 8 & 64 & 0 & 0 & 6 & 30 \\
\hline SA= strongly agree; A= agree; U=Undecided ; D= disagree; SD= strongly disagree \\
\hline
\end{tabular}

Table 2 indicates a contradiction in responses. Regarding, item one "I am interested in implementing TBLT in the classroom" $56 \%$ of the responses were in agreement , $4 \%$ neutral and $40 \%$ in strong disagreement. , item two "TBLT provides a relaxed atmosphere to promote the target language use" $79 \%$ were in strong disagreement and disagreement while only $16 \%$ agreed with the statement, item three "TBLT activates learners' needs and interests" $37 \%$ strongly agreed, $33 \%$ agreed ,and 14\% were neutral while only $2 \%$ strongly disagreed, item four "TBLT pursues the development of integrated skills in the classroom" $65.1 \%$ strongly agreed , 34\% agreed and there was no disagreement, item five "TBLT gives much psychological burden to teacher as a facilitator" $70 \%$ strongly agreed, $5 \%$ were neutral, $15 \%$ disagreed ,and $10 \%$ strongly disagreed, item six "TBLT requires much preparation time compared to other approaches" $5 \%$ strongly agreed, 10\% agreed, $65 \%$ were neutral , and 20\% strongly disagreed, item seven "TBLT is proper for controlling classroom arrangements"

$77 \%$ strongly agreed, 10\% agreed but only 22\% strongly disagreed and item eight "TBLT materials should be meaningful and purposeful based on the real-world context" $64 \%$ strongly agreed,6\% disagreed and 30\% strongly disagreed.

\section{Discussion}

To address the first research question, the analysis of items 1-7 of the questionnaire revealed that the participant GE instructors had adequate knowledge of the characteristics and concept of 'task'. This could be in line with the conclusions that other scholars have reached to in studying TBLT in Asian context in general and Iranian content in particular (Jeon,2005;Zare,2007; Tabatabaei \&Hadi 2011;Hadi,2012) . They all manifested the traces of a shift toward TBLT and its application of task-based to promote and improve activity-oriented communicative skills. The results, in addition, support the findings of Zare(2007) concerning Iranian Instructors" positive attitude toward the application of TBLT.

\section{Conclusion}

In Iranian General English context for non-English major students, the mere opportunity to have exposure to authentic target language material and practice in group work activities is the 135- minute sessions of GE courses which are prerequisite to ESP courses they will take in the advanced levels. Thus, development of task-based courses will provide this invaluable opportunity for both learners and instructors to make best use of their educational time share. The result of this study in line with the result of other Iranian researchers over TBLT (Zare,2007; Tabatabaei\&Hadi 2011) reflect on the point that Iranian GE instructors at university and particularly those involved in teaching at engineering faculties have adequate knowledge of the concept of TBLT and consider it as a facilitative instructional method which can help learners enjoy cooperation, experience authentic tasks, feel the consideration for their interest and motivation. However, there remain some points of complaint concerning the focus of TBLT on meaning on the one hand and the burden on classroom atmosphere on the other hand. In other words, majority of the instructors do not believe on the limited view of meaning-centeredness approach in TBLT and hold the fact that there might be some instances of focus-on form as well. Yet, there is great tendency to employ TBLT in their classes. 


\section{Pedagogical Suggestions}

Taking the findings of the present study into account, some pedagogical implications can be presented which might well suit the target society of GE English instructors at universities. First, although the results reflect on the positive perception toward TBLT, still instructors need to hold peer discussion sessions to discuss the details of their practical experience and attempt to overcome possible dissatisfaction and drawbacks. Second, to select the task types creatively and apply warm up activities outside the course book can be a tricky issue for the instructors so that they might call the process a burden on the way. Thus, instructors are suggested to head up for team work and cooperation to develop or select the most appropriate tasks to avoid possible disappointment, discouragement and failure. Thirdly, all the instructors need to reconsider their classroom management techniques in general and the timing component in particular. Ignorance would lead toward failure and loss, particularly when the class faces limited number of sessions to cover the assigned syllabus. Finally, the instructors can ask the learners to collaboratively participate in warm-up pre task selection process to have better access to the field of interest to initiate the lessons.

\section{Suggestions for Further Study}

Since the present study focused on engineering faculty and GE instructors' perceptions toward TBLT, the same study can be replicated to explore GE students' perceptions or any other faculty's reactions toward the application of TBLT.

\section{References}

Doughty, C., \&Varela, E.(1998). Communicative focus on form, In Focus on Form in Classroom Second Language Acquisition, eds., Doughty, C. \& Williams, J., Cambridge: Cambridge University Press

Ellis, R.(2000).Task-based research and language pedagogy. Language Teaching Research, 4(3), 139-220.

Ellis, R., Basturkmen, H., \&Loewen, S.(2001). Preemptive Focus on Form in the ESL Classroom. TESOL Quarterly, 35(3), 407-432.

Ellis, R. (2003).Task-based Language Learning and Teaching. Oxford: Oxford University Press.

Estaire, S. \& J. Zanon. (1994). Planning Classwork: A Task Based Approach. Oxford: Heinemann.

Hadi, A. (2012). Perceptions of Task-based Language Teaching: A Study of Iranian EFL Learners.English Language Teaching,6(1): p103.

Jeon, In-Jae. (2005). An Analysis of Task-Based Materials and Performance: Focused on Korean High School English Textbooks. English Teaching, 60(2), 87-109

Kumaradivelu, B.(1993). The name of the task and the task of naming: methodologicalaspects of task based pedagogy. In G. Crookes, G. \& S. Gass,eds.,(1993a)

Lee, J. (2000). Tasks and communicating in Language Classrooms. Boston: McGrowHill.

Lightbown, P. \&Spada.N.(1993).How Languages Are Learned, Oxford: Oxford University Press

Littlewood, W.( 2004). The task-based approach: some questions and suggestions. ELT Journal, 58(4), 319-326

Murphy, L.(2005). Attending to form and meaning: the experience of adult distance learners of French, German and Spanish. Language Teaching Research, 9(3), 295-317.

Nunan, D. (1989). Designing Tasks for the Communicative Classroom. Cambridge:Cambridge University Press.

Nunan, D. (2004). Task-Based Language Teaching. Cambridge: Cambridge University press.

Prabhu, N. S. (1987). Second Language Pedagogy. Oxford: Oxford University Press.

Skehan, P.(1996).A Framework for the implementation of task-based instruction.Applied Linguistics, 17, 38-62.

Skehan, P.(1998).Task-based instruction. Annual Review of Applied Linguistics, 18, 268-286.

Skehan, P. (2003a). Focus on Form, Tasks, and Technology. Computer Assisted Language Learning, 16(5), 391-411.

Skehan, P.( 2003b).Task-based instruction. Language Teaching, 36, 1-34.

Skehan, P., \& Foster, P. (1997). Task type and task processing conditions as influences on foreign language performance. Language Teaching Research, 1(3), 185-211.

Tabatabaie, O. \&Hadi, A. (2011). Iranian EFL Teachers' Perceptions of Task-Based Language Pedagogy. Higher Education of Social Science.1, (2), 1-9.

Willis, J. (1996).A Framework for Task-Based Learning.Harlow: Longman.

Willis, D. \& J. Willis. (1996). Consciousness-raising activities in the language classroom. In J. Willis \&D. Willis(ed). Challenge and Change in Language Teaching. Oxford: Heinemann.

Zare, G. (2007). The Attitudes of the Iranian EFL Learners and Teachers Towards Task-based Language Teaching. (Unpublished MA thesis).Shiraz University, Shiraz, Iran. 